\title{
Bicycling, Birding and \#BLM across America in a Summer of Chaos
}

\author{
Scott V. Edwards $\ddagger$ \\ ‡ Harvard University, Cambridge, United States of America
}

Corresponding author: Scott V. Edwards (sedwards@fas.harvard.edu)

Received: 03 Oct 2020 | Published: 05 Oct 2020

Citation: Edwards SV (2020) Bicycling, Birding and \#BLM across America in a Summer of Chaos. Biodiversity Information Science and Standards 4: e59303. https://doi.org/10.3897/biss.4.59303

\begin{abstract}
From 6 June to 20 August, 2020, I undertook a 76-day, 3800 mile bicycle trip across the United States from the Atlantic to the Pacific oceans. In this talk I will share with you some of the amazing people, landscapes and birds I encountered, mostly in rural towns and along blue highways. The gradually changing birdscape, both in sight and sound, underscored the sensitive ecological gradients to which birds respond, as well as the ability of some species to thrive in agricultural monocultures. Rivers large and small regularly benchmarked my progress, as well as the western journey of Lewis \& Clark over 200 years ago. The recent incidents in the US involving African Americans as targets of white violence inexorably caused me to festoon my bicycle with \#BlackLivesMatter (\#BLM) signs and share my experiences on social media. I encountered a variety of reactions, often positive and occasionally sharply negative, in a sea of generosity and extraordinary kindness as I wheeled my way through towns on the brink of collapse, vast private ranches and the occasional city. Rural America exhibits an abundance of loyalty and empathy for local communities, yet it is sometimes hard for Americans - myself included - to empathize with people they have never met in person. Two imperatives I took away, with ramifications for both biodiversity and political stability, were the need to somehow bring divergent communities together and to encourage empathy at the national level, among communities that otherwise experience each other only on TV.
\end{abstract}


Presenting author

Scott V. Edwards

\section{Presented at}

TDWG 2020 